\title{
A Simple Fractal-Based Model for Soil-Water Characteristic Curves Incorporating Effects of Initial Void Ratios
}

\author{
Gaoliang Tao ${ }^{1}{ }^{(\mathbb{0})}$, Yin Chen ${ }^{1}{ }^{(\mathbb{D})}$, Lingwei Kong ${ }^{2}{ }^{(\mathbb{C})}$, Henglin Xiao ${ }^{1}$, Qingsheng Chen ${ }^{1, *}$ and \\ Yuxuan $\mathrm{Xia}^{3}$ \\ 1 Hubei Provincial Ecological Road Engineering Technology Research Center, Hubei University of Technology, \\ Wuhan 430068, China; tgl1979@126.com (G.T.); agchen19930922@163.com (Y.C.); \\ xiao-henglin@163.com (H.X.) \\ 2 State Key Laboratory of Geomechanics and Geotechnical Engineering, Institute of Rock and Soil Mechanics, \\ Chinese Academy of Sciences, Wuhan 430071, China; lwkong@whrsm.ac.cn \\ 3 Hubei Subsurface Multi-Scale Imaging Key Laboratory, Institute of Geophysics and Geomatics, China \\ University of Geosciences, Wuhan 430074, China; xiayx@cug.edu.cn \\ * Correspondence: chqsh2006@163.com
}

Received: 25 April 2018; Accepted: 29 May 2018; Published: 1 June 2018

\begin{abstract}
In this paper, a simple and efficient fractal-based approach is presented for capturing the effects of initial void ratio on the soil-water characteristic curve (SWCC) in a deformable unsaturated soil. In terms of testing results, the SWCCs (expressed by gravimetric water content) of the unsaturated soils at different initial void ratios were found to be mainly controlled by the air-entry value $\left(\psi_{\mathrm{a}}\right)$, while the fractal dimension $(D)$ could be assumed to be constant. As a result, in contrast to the complexity of existing models, a simple and efficient model with only two parameters (i.e., $D$ and $\psi_{\mathrm{a}}$ ) was established for predicting the SWCC considering the effects of initial void ratio. The procedure for determining the model parameters with clear physical meaning were then elaborated. The applicability and accuracy of the proposed model were well demonstrated by comparing its predictions with four sets of independent experimental data from the tests conducted in current work, as well as the literature on a wide range of soils, including Wuhan Clay, Hefei and Guangxi expansive soil, Saskatchewan silt, and loess. Good agreements were obtained between the experimental data and the model predictions in all of the cases considered.
\end{abstract}

Keywords: soil-water characteristic curve; initial void ratio; air-entry value; fractal dimension; fractal model

\section{Introduction}

The soil-water characteristic curve (SWCC) of a soil reflects the relationship between volumetric water content and matric suction. It is a useful tool for indicating the hydraulic properties of the soil and has various applications in the field of unsaturated soil mechanics, such as strength theory, percolation theory, consolidation theory, and constitutive theory [1-5]. The SWCC is also commonly employed in estimating the shear strength, stress-strain relationships, and permeability of unsaturated soils [6-8].

Over the past decades, a large number of studies have been carried out on the SWCCs of unsaturated soils [6-10]. It has been recognized that SWCCs are affected by various factors, such as pore-size distribution (PSD), particle-size distribution, and dry density [11,12]. One specific factor that affects the SWCC is the porosity of the soil, which can change considerably for the soils with variation of stress and suction states, as well as the stress and suction history of the soil [13]. Zhou et al. [14] 
reported that the samples of a given soil with different void ratios could be regarded as entirely different soils. As also stated by Assouline [15], a change of soil porosity can result in a significant change of SWCC, and such a change in soil porosity is a common feature of natural soils.

In recent decades, the issue of the effect of soil porosity on the hydraulic properties of a soil has received great attentions of various researchers [16-24]. In the meanwhile, various models have been proposed to account for the effect of initial void ratio on SWCCs. For example, Van Genuchten [6] proposed an equation to empirically describe the SWCC data, in which there are three parameters and the parameter $\alpha$ is the main influence factor of air-entry value. Gallipoli et al. [17] modified the equation by assuming the parameter $\alpha$ to be related to the void ratio by a power law. Tarantino [25] presented a void ratio-dependent SWCC model. For high suction stage, it was assumed that the initial void ratio has insignificant influence on the SWCC data, with a result that the SWCC could be represented by a single equation. This model is very similar to the model proposed by Gallipoli et al. [17], but it incorporates one parameter less than Gallipoli's model. Masin [23] proposed a hydraulic model that is capable of capturing the dependence of the degree of saturation on the void ratio and suction using the effective stress principle. In this model, three material parameters were required. Most recently, Zhou et al. [14] proposed a method to take account of the effects of initial void ratio on SWCC through introducing one more additional parameter in the existing empirical SWCC equations. Gallipoli et al. [26] formulated an SWCC model considering the effects of hysteresis and void ratio of the soils with various degrees of saturation. However, there are seven parameters in this model. Although substantial contributions have been made in the above models for predicting the water retention behavior of unsaturated soils, the application of these models are still largely restricted due to their complexity. As a result, it is of immense necessity to propose a simple and efficient approach with fewer parameters for estimating the SWCC of unsaturated soils, so that the engineers can readily apply it in practice.

Recently, fractal theory has been increasingly recognized as a useful tool to analyze the physico-geometrical properties (e.g., particle-size distribution, pore volume, and pore surface) of porous media [27-31]. It was pointed out that the hydraulic characteristics of porous media are closely related to its pore characteristics [32], thus, fractal theory is also suitable to describe the hydraulic characteristics of porous media. Shi et al. [33] developed a fractal model for describing the spontaneous imbibition of wetting phase into the porous media. Most recently, some researchers have also devoted to fractal-based SWCC model [34-36]. It was reported that this approach is capable of combining the empirical models with the parameters with clear physical meaning, and it can also be readily applied in engineering practice [37]. Nevertheless, most of existing fractal-based SWCC models could not account for the effects of void ratios of soils. Most recently, Khalili et al. [38] proposed a fractal-based model considering volume change, and the fractal dimension of PSD in the model was taken to be void ratio dependent, however, this model has seven parameters, which are not easily determined. Meanwhile, it has been verified for clayey silty sand only.

To address the above issues, this paper presents a simple and efficient SWCC model incorporating the effects of initial void ratios by employing the fractal theory. On the basis of experimental results, the SWCCs of the soils at different initial void ratios were found to be mainly controlled by air-entry value, while fractal dimension can be seen as a constant. Combined with fractal theory, a new model for predicting the air-entry value was proposed. Thereafter, a simple and efficient SWCC model capable of predicting the SWCCs at deformed state considering the effects of initial void ratio was established. In contrast to the complexity of existing models, only two parameters are needed in the proposed model. The applicability and accuracy of this model were demonstrated by comparing its predictions with four sets of independent experimental data from the tests conducted in current work, as well as the literatures. Good agreement was obtained between the experimental data and the model predictions in all of the cases considered. 


\section{Proposed Model}

\subsection{Fractal Description of a Soil}

Assuming continuous pore-size distribution (PSD) over a range of pore sizes $(r)$ between $r_{\min }$ and $r_{\max }$ in which $r_{\min }$ and $r_{\max }$ are the smallest and largest pores, respectively, the probability density function of pore size $r$ is written as [39]

$$
f(r)=c r^{-1-D}
$$

where $c$ is a constant, $D$ is the fractal dimension, and $r$ is the effective pore size of the connected pore channel. It is assumed that the minimum pore size $r_{\min }$ is near zero. Then, the total volume $V(\leq r)$ of pores having size less than or equal to $r$ can be expressed as

$$
V(\leq r)=\int_{0}^{r} c r^{-1-D} k_{\mathrm{V}} r^{3} d r=\frac{c k_{\mathrm{V}}}{3-D} r^{3-D}
$$

where $k_{\mathrm{v}}$ is a pore volume shape-related constant corresponding to the volume of the pores. Assuming that pores having a size less than or equal to $r$ are fully filled with water, then the gravimetric water content in the pores of soil particles weighing $1 \mathrm{~g}$ is

$$
w=\rho_{\mathrm{w}} V(\leq r)=\frac{c \rho_{\mathrm{w}} k_{\mathrm{V}}}{3-D} r^{3-D}
$$

where $\rho_{\mathrm{w}}$ is the mass density of water.

The soil sample is regarded as fully saturated soil when the largest pores with $r_{\max }$ are filled with water. Then, substituting $r$ with $r_{\max }$ in Equation (3) yields the following expression

$$
w_{\mathrm{s}}=\frac{c \rho_{\mathrm{w}} k_{\mathrm{V}}}{3-D} r_{\max }^{3-D}
$$

where $w_{\mathrm{s}}$ is gravimetric water content of the soil in saturated condition.

\subsection{Fractal-Based Model for Variation of Soil-Water Characteristic Curve (SWCC) with Initial Void Ratio}

According to the Young-Laplace equation, the relationship between matrix suction $\psi$ and effective pore size $r$ can be described as

$$
\psi=2 T_{\mathrm{s}} \cos \alpha / r
$$

where $T_{S}$ is the surface tension and $\alpha$ is the contact angle. In the constant temperature condition, $2 T_{s} \cos \alpha$ can be assumed as a constant. The matrix suction $\psi$ corresponding to maximum pore size can be approximately regarded as the air-entry value $\psi_{\mathrm{a}}$, which can be captured by substituting $r$ with $r_{\max }$ in Equation (5)

$$
\psi_{\mathrm{a}}=2 T_{\mathrm{s}} \cos \alpha / r_{\max }
$$

Then, substituting Equation (5) into Equation (3), and Equation (6) into Equation (4), respectively, yields the following expressions

$$
\begin{aligned}
& w=\frac{c \rho_{\mathrm{w}} k_{\mathrm{V}}}{3-D}\left(\frac{2 T_{\mathrm{s}} \cos \alpha}{\psi}\right)^{3-D} \\
& w_{\mathrm{s}}=\frac{c \rho_{\mathrm{w}} k_{\mathrm{V}}}{3-D}\left(\frac{2 T_{\mathrm{s}} \cos \alpha}{\psi_{\mathrm{a}}}\right)^{3-D}
\end{aligned}
$$

Dividing Equation (8) by Equation (7) gives

$$
\frac{w}{w_{\mathrm{s}}}=\left(\frac{\psi_{\mathrm{a}}}{\psi}\right)^{3-D}
$$


Note that Equations (7) and (9) are only valid in the range of $\psi \geq \psi_{\mathrm{a}}$. If matrix suction $\psi$ is less than $\psi_{a}$, the soil sample is assumed to be fully saturated. Then, the fractal model for soil-water characteristic curve is written as

$$
\left\{\begin{array}{cc}
\frac{w}{w_{\mathrm{s}}}=\left(\frac{\psi_{\mathrm{a}}}{\psi}\right)^{3-D} & \psi \geq \psi_{\mathrm{a}} \\
w=w_{\mathrm{s}} & \psi<\psi_{\mathrm{a}}
\end{array}\right.
$$

In the saturated condition, the water content of soil can be determined by

$$
w_{s}=\frac{e}{G_{s}}
$$

where $G_{s}$ is the relative density and $e$ refers to the initial void ratio.

Then, the variation of SWCC with void ratio can be captured by substituting Equation (11) into Equation (10)

$$
\left\{\begin{array}{cc}
w=\frac{e}{G_{\mathrm{s}}}\left(\frac{\psi_{\mathrm{a}}}{\psi}\right)^{3-D} & \psi \geq \psi_{\mathrm{a}} \\
w=\frac{e}{G_{\mathrm{s}}} & \psi<\psi_{\mathrm{a}}
\end{array}\right.
$$

\subsection{Determination of Model Parameters}

The main objective of this study is to predict the SWCCs at the deformed state considering the effects of initial void ratio. It should be noted that the SWCC at the reference state is corresponding to the experimental soil sample with the maximum initial void ratio $e_{0}$, while the SWCCs at the deformed state refer to the experimental soil samples with the other arbitrary initial void ratio $e_{1}\left(e_{1}<e_{0}\right)$. As observed in Equation (12), the prediction of SWCCs at arbitrary initial void ratio is mainly governed by only two parameters: (i) fractal dimension $D$ and (ii) air-entry value $\psi_{\mathrm{a}}$ at the deformed state. The procedure for determining the model parameters (i.e., $D$ and $\psi_{\mathrm{a}}$ ) are now elaborated as follows.

\subsubsection{Fractal Dimension at Reference State}

By taking the logarithm of both sides of Equation (7), it could be rewritten as

$$
\begin{aligned}
\ln w & =\ln \frac{c \rho_{w} k_{v}}{3-D}\left(\frac{2 T_{s} \cos \alpha}{\psi}\right)^{3-D} \\
& =\ln \frac{c \rho_{w} k_{v}}{3-D}+(3-D) \ln \frac{2 T_{s} \cos \alpha}{\psi} \\
& =(3-D)\left[\ln 2 T_{s} \cos \alpha-\ln \psi\right]+\ln \frac{c \rho_{w} k_{v}}{3-D} \\
& =(3-D)(-\ln \psi)+\ln \left[\frac{c \rho_{w} k_{v}}{3-D}\left(2 T_{s} \cos \alpha\right)^{3-D}\right]
\end{aligned}
$$

Then, it is easy to obtain Equation (13)

$$
\ln w \propto(3-D)(-\ln \psi)
$$

By plotting the $\ln w$ against $(-\ln \psi),(3-D)$ can be evaluated from the gradient $k$ of the graph, then the fractal dimension can be determined as $D=3-k$.

\subsubsection{Fractal Dimension at Deformed State}

Based on the experimental data, it was found by Tao et al. [40] that SWCC expressed by gravimetric water content at different initial void ratios presents a type of "broom shape" distribution. More precisely, SWCCs at different initial void ratios are almost consistent when the high matrix suction is greater than air-entry value. As shown in Figure 1, SWCCs corresponding to initial void ratio $e_{0}, e_{1}$, and $e_{2}$ (i.e., a-b-c-d, e-b-c-d, and f-c-d) almost overlap at the tail. It should be noted that the SWCC is expressed by gravimetric water content herein. As a result, the fractal dimension $D_{1}$ for $e_{1}$ at deformed state is approximatively equal to the fractal dimension $D_{0}$ for $e_{0}$ at reference state. That is, the fractal dimension $D$ of saturated soil at deformed state can be assumed as a constant (i.e., $D_{1}=D_{0}$ ). 
It should be highlighted that similar ideas have been presented by Bird et al. [34] and Russell and Buzzi [41].

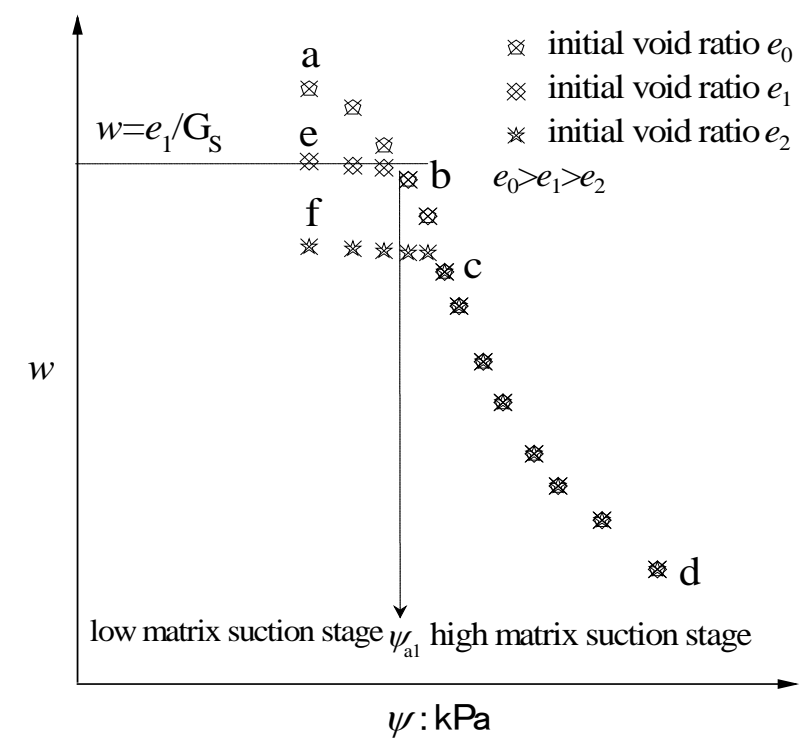

Figure 1. Schematic sketch of soil-water characteristic curves (SWCCs) in terms of gravimetric water content of unsaturated soils with different initial void ratios.

\subsubsection{Air-Entry Value at Reference State}

If the SWCC at reference state is measured, the corresponding fractal dimension $D_{0}$ can be calculated by following the procedure described above, and the air-entry value $\psi_{\mathrm{a} 0}$ can be determined by best fitting Equation (12) to the experimental SWCCs. Then, the SWCC at reference state can be expressed as

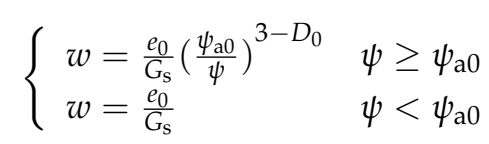

\subsubsection{Air-Entry Value at Deformed State}

Drawing a horizontal line $w=e_{1} / G_{s}$, the horizontal line would have an intersection with the SWCC at reference state. The abscissa of this intersection can be approximately regarded as $\psi_{\mathrm{a} 1}$ corresponding to $e_{1}$, as shown in Figure 1. By substituting $w=e_{1} / G_{s}$ into the first formula in Equation (14), the following expression is obtained

$$
\frac{e_{1}}{e_{0}}=\left(\frac{\psi_{\mathrm{a} 0}}{\psi}\right)^{3-D_{0}}
$$

Equation (15) can be then simplified to

$$
\psi=\frac{\psi_{\mathrm{a} 0}}{\left(\frac{e_{1}}{e_{0}}\right)^{1 /\left(3-D_{0}\right)}}
$$

The matrix suction expressed by Equation (16) is approximately considered as air-entry value $\psi_{\mathrm{a} 1}$ for $e_{1}$.

\section{Model Validation}

To demonstrate the performance of the proposed fractal model (Equation (12)) for SWCCs of unsaturated soils considering effects of the initial void ratio, a series of simulations were carried out using a set of independent laboratory tests conducted in the current work, as well as by others in the 
literatures [42-44] on a wide range of soils, including Wuhan Clay, Hefei and Guangxi expansive soil, Saskatchewan silt, and loess. The comparisons and discussions are presented as follows.

\subsection{Wuhan Clay}

Pressure plate tests were conducted to determine the SWCCs for samples of clay collected from the bottom of a foundation ditch in Wuhan, China. The basic physical property index of soil is shown in Table 1. The experiment was completed at the Institute of Rock and Soil Mechanics, Wuhan Institute of Chinese Academy of Sciences. The pressure plate instrument used in the experiment, which consists of pressure cell, higher air-entry value (HAE) ceramic disc, pressure gage, and nitrogen source, is shown in Figure 2.

Table 1. Basic physical property index of Wuhan clay.

\begin{tabular}{ccccc}
\hline $\begin{array}{c}\text { Natural Density } \\
\left(\mathbf{g} / \mathrm{cm}^{3}\right)\end{array}$ & Relative Density & $\begin{array}{c}\text { Natural Water } \\
\text { Content (\%) }\end{array}$ & Liquid Limit (\%) & Plastic Limit (\%) \\
\hline 2.03 & 2.75 & 21.9 & 38.9 & 20.4 \\
\hline
\end{tabular}

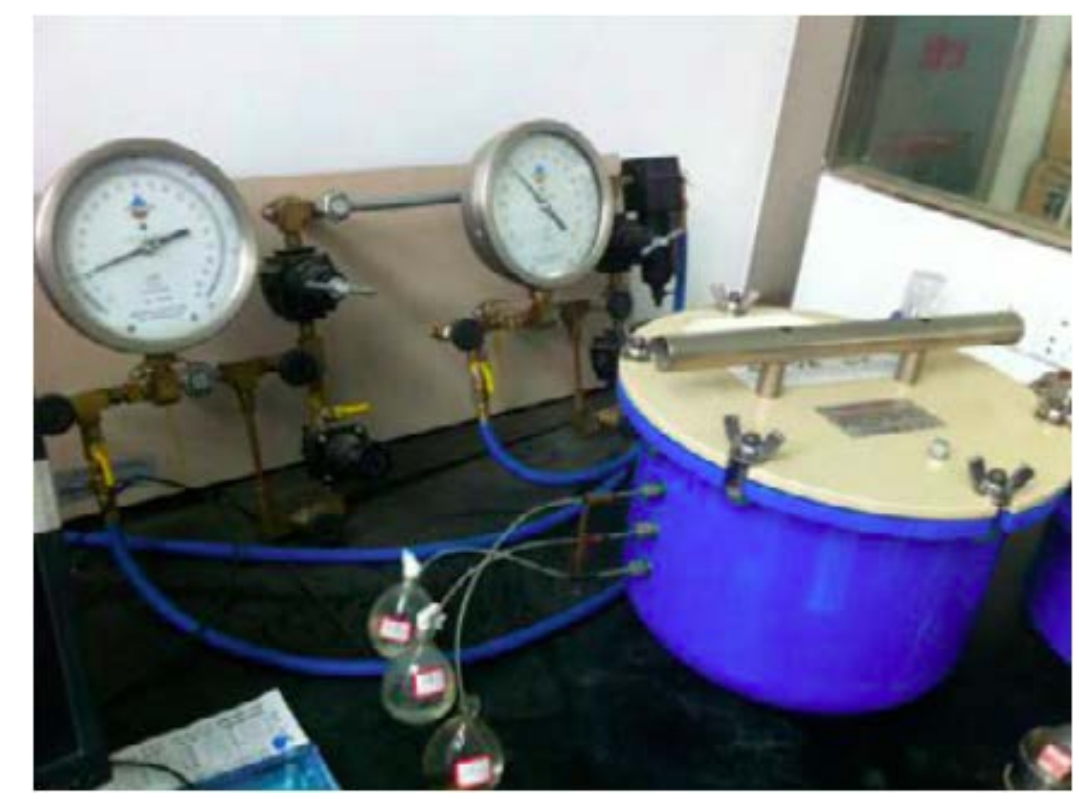

Figure 2. Pressure plate apparatus instrument.

In the tests, seven samples were compacted using hydraulic jack to form different initial dry densities, ranging from 1.30 to $1.71 \mathrm{~g} / \mathrm{cm}^{3}$. The specific test procedure is as follows: (1) The sample with different dry densities, together with the HAE ceramic disc, was saturated. (2) The specimen, together with the stainless steel cutting rings, was placed on the HAE ceramic disc in the pressure cell. (3) The applied air pressure was imposed on the specimen when the pressure cell was sealed. (4) The water drained from the specimens was recorded during the whole process of the test. It was assumed to reach the equilibrium state at the current suction level when the water drainage of specimen was constant, then the next suction level would be imposed. (5) At the end of each suction level step, the drainage valve was closed and then the applied air pressure was released. Meanwhile, the weights of specimens needed to be measured. (6) The above-mentioned procedure was repeated until the whole test was completed.

The initial void ratio of the specimen at the loosest state $\left(e_{0}=1.115\right)$ was regarded as the reference state. Following the procedure presented previously, the fractal dimension for the Wuhan Clay at reference state was determined as $D_{0}=2.869$, with a fitting correlation coefficient of up to 0.99 , while the 
air-entry value at reference state was estimated to be $\psi_{\mathrm{a} 0}=1.66 \mathrm{kPa}$ by fitting Equation (12) to the experimental SWCCs, as shown in Figures 3 and 4, respectively.

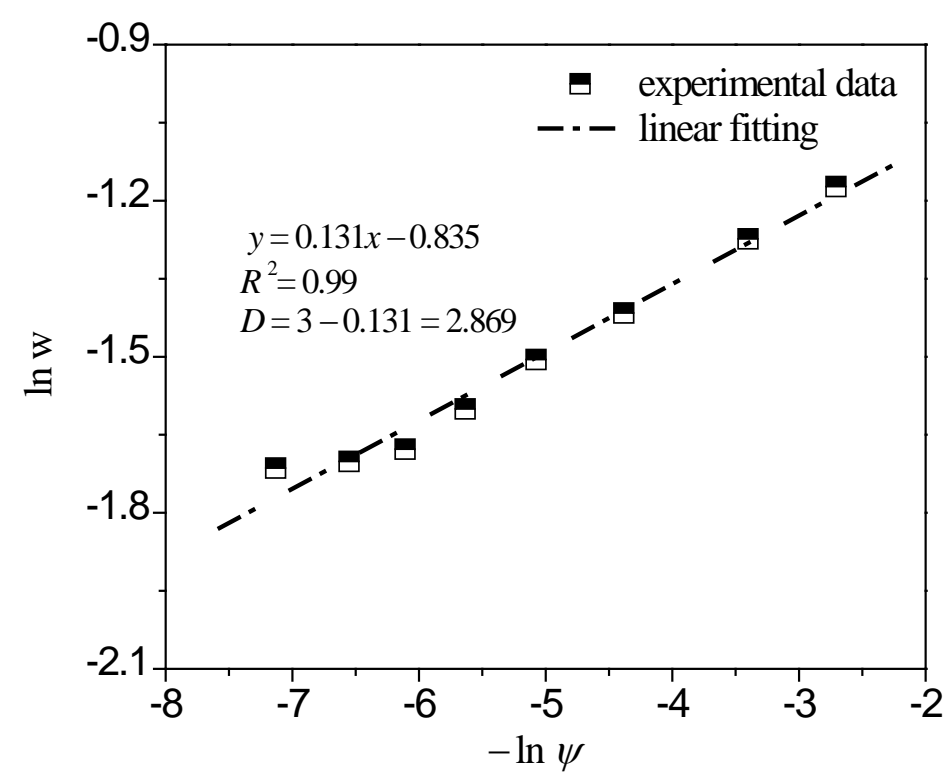

Figure 3. Determination of the values of fractal dimension at reference state through plotting experimental data of $\ln w$ against $(-\ln \psi)$ for Wuhan Clay with $e_{0}=1.115$.

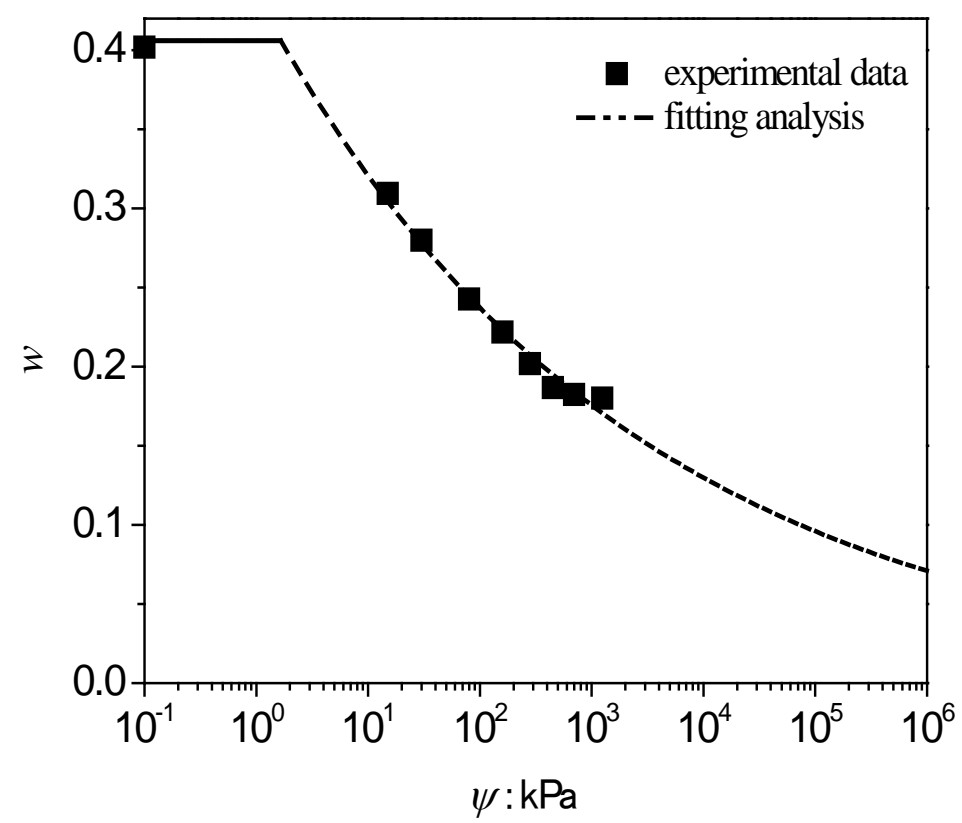

Figure 4. Determination of air-entry values at reference state through fitting Equation (12) to the experimental SWCCs for Wuhan Clay with $e_{0}=1.115$.

As a result, the air-entry values $\psi_{\mathrm{a}}$ of Wuhan Clay at deformed state were determined using Equation (16), as shown in Table 2. 
Table 2. Predictions of fractal dimensions and air-entry values at deformed state.

\begin{tabular}{|c|c|c|c|c|c|c|c|}
\hline Soil Type & $\begin{array}{c}\text { Initial Void } \\
\text { Ratio }\end{array}$ & $\begin{array}{c}\text { Fractal } \\
\text { Dimension }\end{array}$ & $\begin{array}{c}\text { Air-Entry } \\
\text { Value/kPa }\end{array}$ & Soil Type & $\begin{array}{c}\text { Initial Void } \\
\text { Ratio }\end{array}$ & $\begin{array}{c}\text { Fractal } \\
\text { Dimension }\end{array}$ & $\begin{array}{c}\text { Air-Entry } \\
\text { Value/kPa }\end{array}$ \\
\hline Wuhan clay & $\begin{array}{l}1.037 \\
0.964 \\
0.897 \\
0.833 \\
0.719 \\
0.613\end{array}$ & 2.869 & $\begin{array}{c}2.89 \\
5.04 \\
8.74 \\
15.37 \\
47.28 \\
159.74\end{array}$ & $\begin{array}{l}\text { Saskatchewan } \\
\text { silt/T1 }\end{array}$ & $\begin{array}{c}0.54 \\
0.528 \\
0.501 \\
0.483 \\
0.466\end{array}$ & 2.640 & $\begin{array}{l}15.50 \\
16.50 \\
19.08 \\
21.12 \\
23.33\end{array}$ \\
\hline Hefei expansive soil & $\begin{array}{l}0.838 \\
0.766\end{array}$ & 2.514 & $\begin{array}{l}60.58 \\
72.89\end{array}$ & $\begin{array}{l}\text { Saskatchewan } \\
\text { silt/T2 }\end{array}$ & $\begin{array}{l}0.513 \\
0.490 \\
0.474 \\
0.454 \\
0.426\end{array}$ & 2.604 & $\begin{array}{l}18.77 \\
21.08 \\
22.92 \\
25.56 \\
30.02\end{array}$ \\
\hline Guangxi expansive soil & $\begin{array}{l}0.824 \\
0.753\end{array}$ & 2.589 & $\begin{array}{l}33.28 \\
41.44\end{array}$ & $\begin{array}{c}\text { Xian } \\
\text { Loess }\left(5^{\circ} \mathrm{C}\right)\end{array}$ & $\begin{array}{l}0.88 \\
0.75 \\
0.72\end{array}$ & 2.825 & $\begin{array}{c}3.73 \\
9.29 \\
11.73\end{array}$ \\
\hline
\end{tabular}

Figure 5 demonstrates that the calculated SWCCs at deformed state using the proposed model (Equation (12)) agree well with the experimental data of Wuhan Clay at various void ratios (i.e., $e_{0}=1.037$, $0.964,0.897,0.833,0.719$, and 0.613 , respectively).

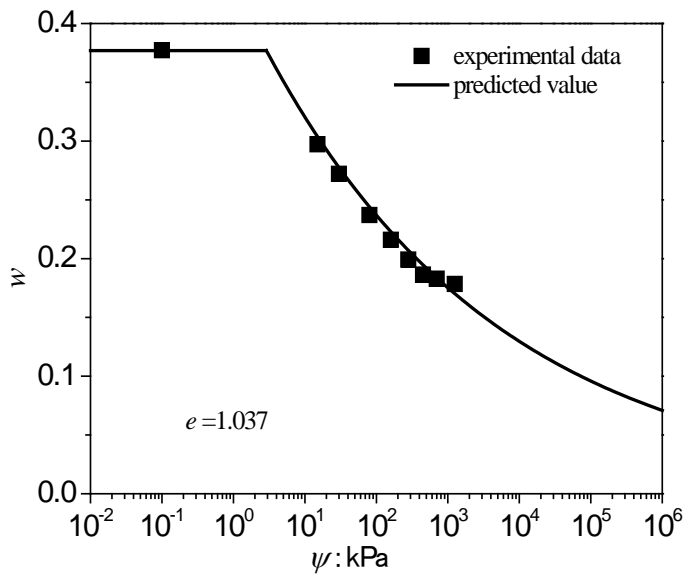

(a)

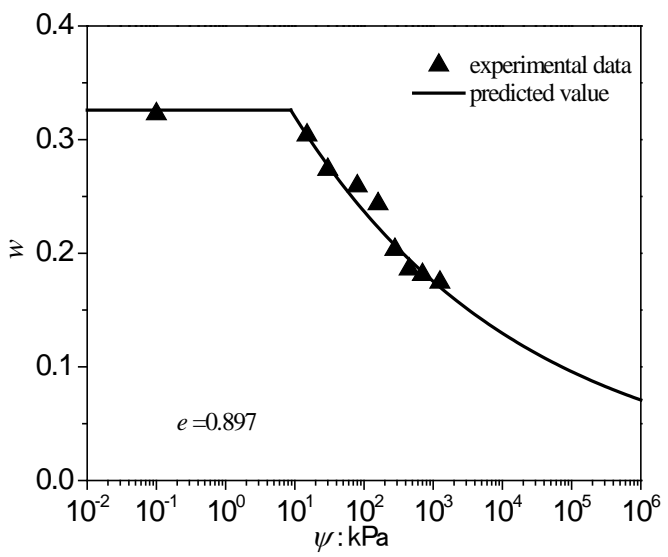

(c)

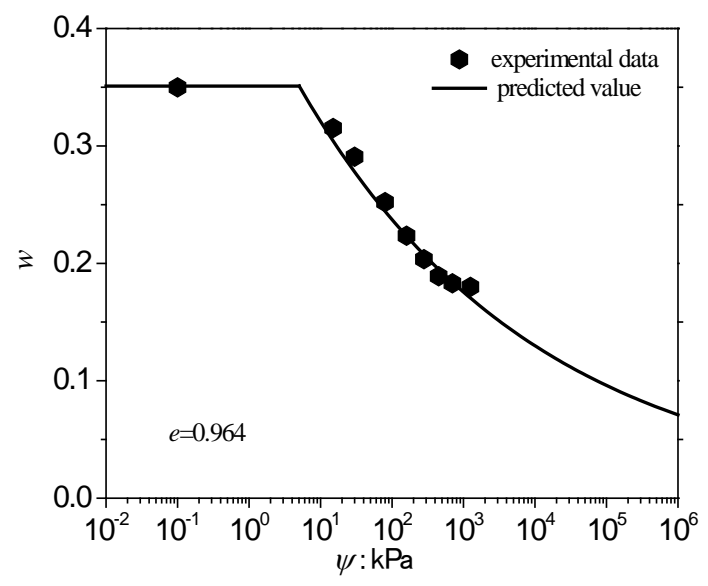

(b)

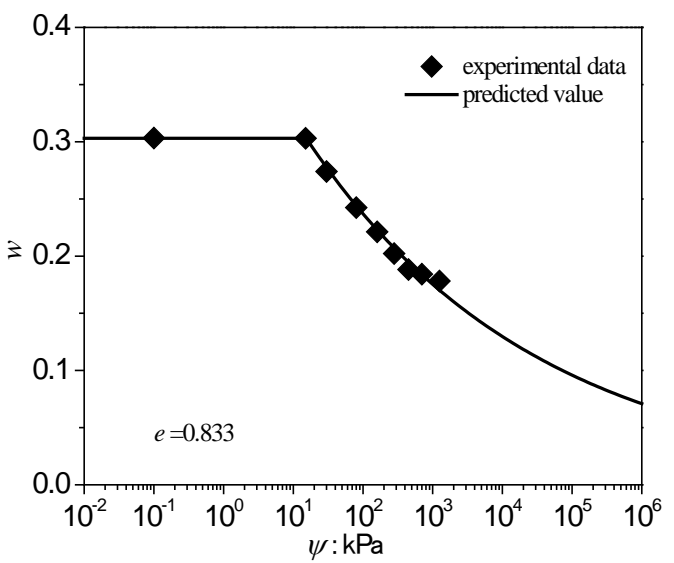

(d)

Figure 5. Cont. 


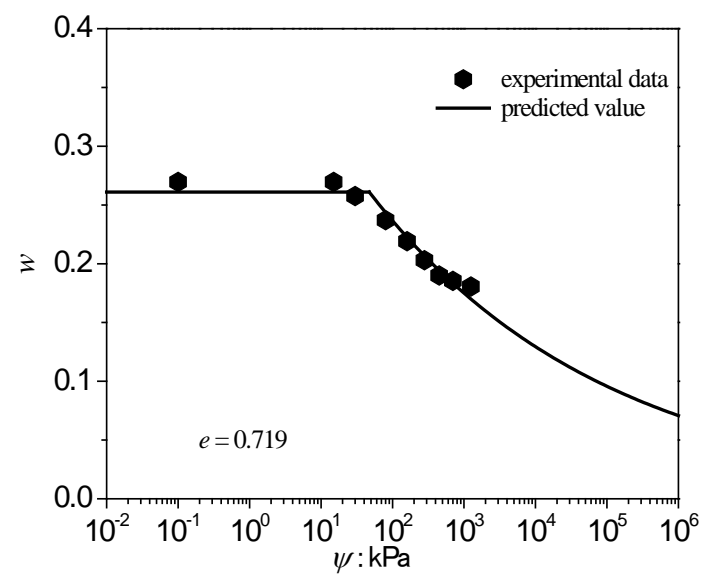

(e)

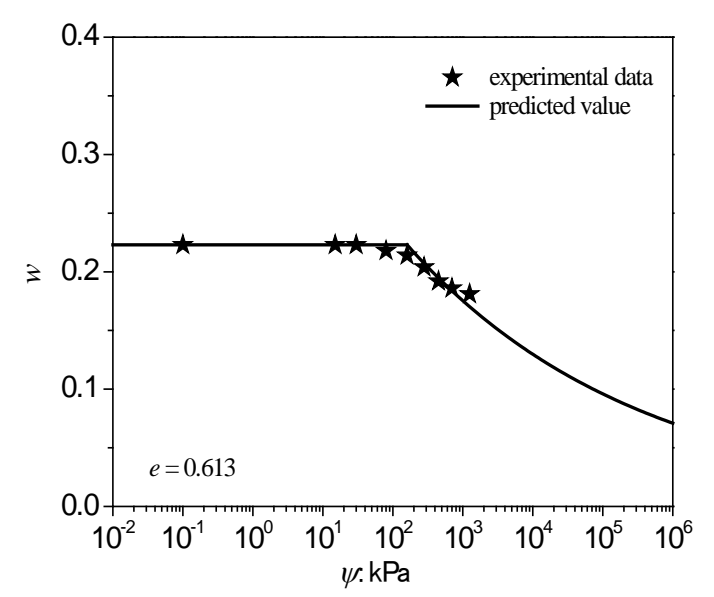

(f)

Figure 5. Measured and predicted SWCCs for Wuhan clay at deformed state at (a) $e=1.037 ;(\mathbf{b}) e=0.964$; (c) $e=0.897 ;(\mathbf{d}) e=0.833 ;(\mathbf{e}) e=0.719 ;(\mathbf{f}) e=0.613$.

\subsection{Hefei and Guangxi Expansive Soils}

Miao et al. [42] performed a series of pressure plate tests on Hefei and Guangxi expansive soil, where the specimens were compacted by the static compaction in steel rings at three dry densities, $1.42 \mathrm{~g} / \mathrm{cm}^{3}, 1.48 \mathrm{~g} / \mathrm{cm}^{3}, 1.54 \mathrm{~g} / \mathrm{cm}^{3}$, respectively. The physical properties of Hefei and Guangxi expansive soils are summarized in Tables 3 and 4, respectively. The void ratios of the specimens at the loosest state $\left(e_{0}=0.915\right.$ for Hefei expansive soil, $e_{0}=0.901$ for Guangxi expansive soil) were regarded as the initial void ratios at reference state.

Similarly, the parameters at reference state for Hefei expansive soil $\left(D_{0}=2.514, \psi_{\mathrm{a} 0}=50.56 \mathrm{kPa}\right)$ were obtained as shown in Figures 6 and 7, respectively, while the corresponding air-entry values $\psi_{\mathrm{a}}$ at deformed state were determined using Equation (16), as shown in Table 2. As can be seen in Figure 6, the fitting correlation coefficients for fractal dimension are up to 0.98 , indicating that the SWCCs of Hefei specimens have obvious fractal features.

Table 3. Physical properties of Hefei expansive soils (data after Miao et al. [42]).

\begin{tabular}{cccc}
\hline Relative Density & Liquid Limit (\%) & Plastic Limit (\%) & Plasticity Index (\%) \\
\hline 2.72 & 58.6 & 26.4 & 32.2 \\
\hline
\end{tabular}

Table 4. Physical properties of Guangxi expansive soils (data after Miao et al. [42]).

\begin{tabular}{cccc}
\hline Relative Density & Liquid Limit (\%) & Plastic Limit (\%) & Plasticity Index (\%) \\
\hline 2.70 & 61.4 & 30.3 & 31.1 \\
\hline
\end{tabular}




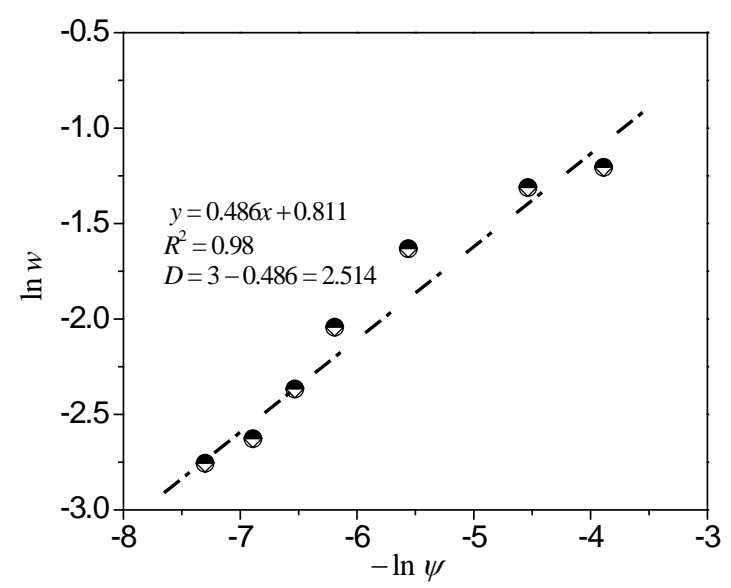

Figure 6. Determination of the values of fractal dimension at reference state through plotting experimental data of $\ln w$ against $(-\ln \psi)$ for Hefei expansive soil with $e_{0}=0.915$.

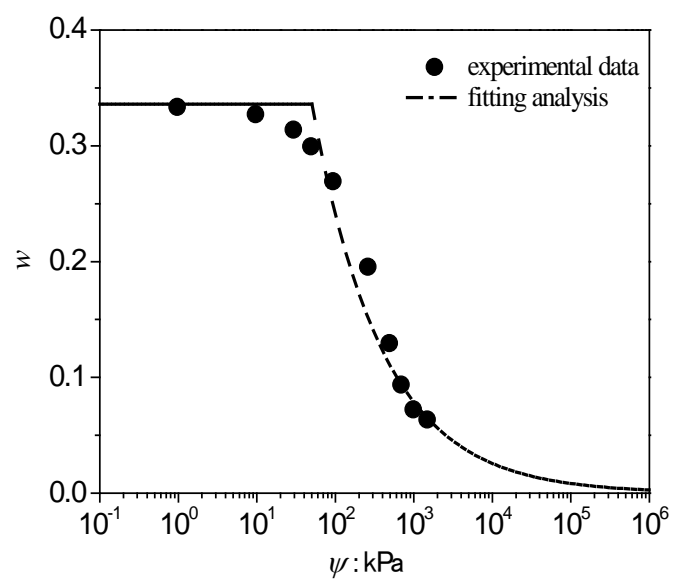

Figure 7. Determination of air-entry values at reference state through fitting Equation (12) to the experimental SWCCs for Hefei expansive soil with $e_{0}=0.915$.

Figure 8 indicates that the SWCCs computed by the current model compared well with the laboratory data of the unsaturated Hefei expansive soils at all initial void ratios.

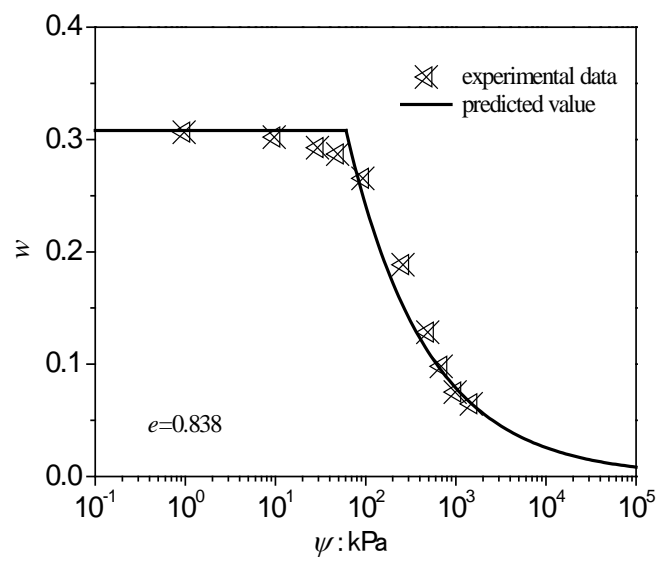

(a)

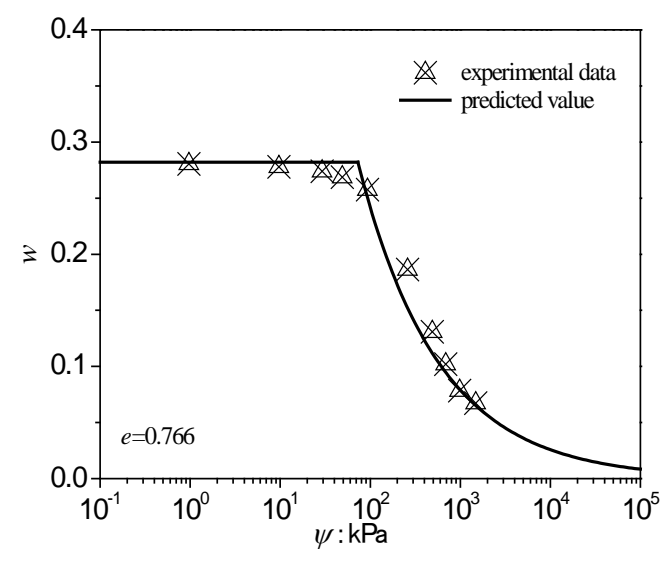

(b)

Figure 8. Measured and predicted SWCCs for Hefei expansive soils at deformed state at (a) $e=0.838$; (b) $e=0.766$ (data after Miao et al. [42]). 
The parameters at reference state for Guangxi expansive soils $\left(D_{0}=2.589, \psi_{\mathrm{a} 0}=26.78 \mathrm{kPa}\right)$ were obtained as shown in Figures 9 and 10, respectively, while the corresponding air-entry values $\psi_{\mathrm{a}}$ at deformed state were determined using Equation (16), as shown in Table 2. As can be seen in Figure 9, the fitting correlation coefficients for fractal dimension are up to 0.97 , indicating that the SWCCs of Guangxi specimens have obvious fractal features.

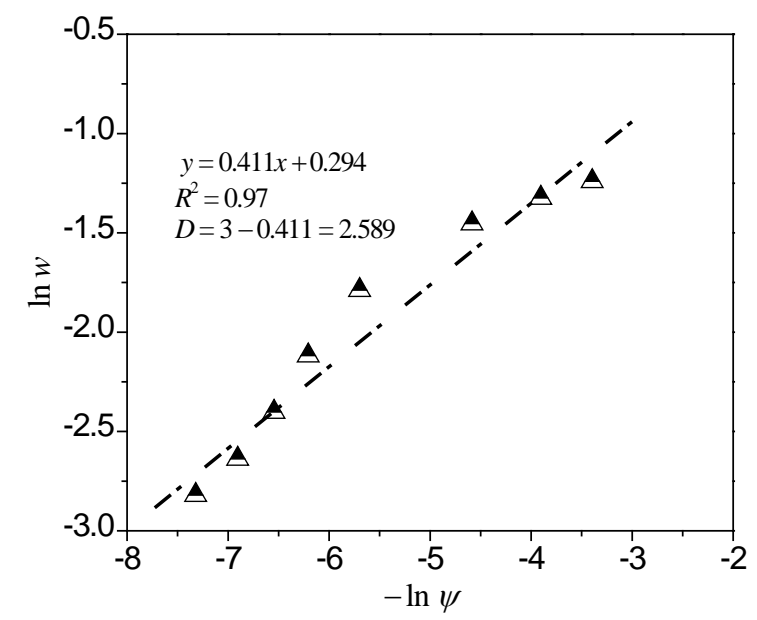

Figure 9. Determination of the values of fractal dimension at reference state through plotting experimental data of $\ln w$ against $(-\ln \psi)$ for Guangxi expansive soil with $e_{0}=0.901$.

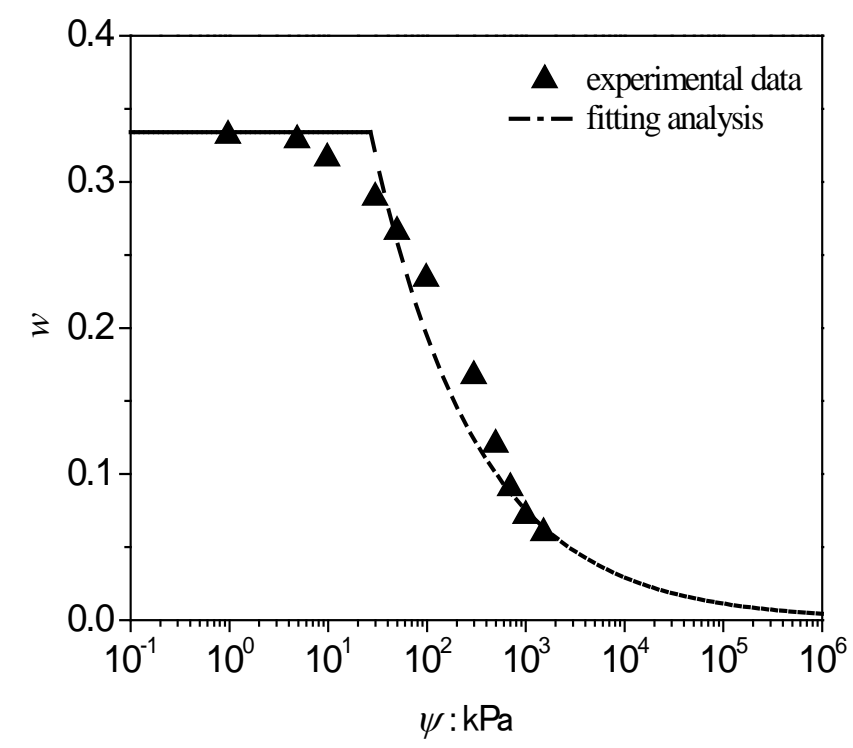

Figure 10. Determination of air-entry values at reference state through fitting Equation (12) to the experimental SWCCs for Guangxi expansive soil with $e_{0}=0.901$.

Figure 11 indicates that the SWCCs computed by the current model compared well with the laboratory data of the unsaturated Guangxi expansive soils at all initial void ratios. 


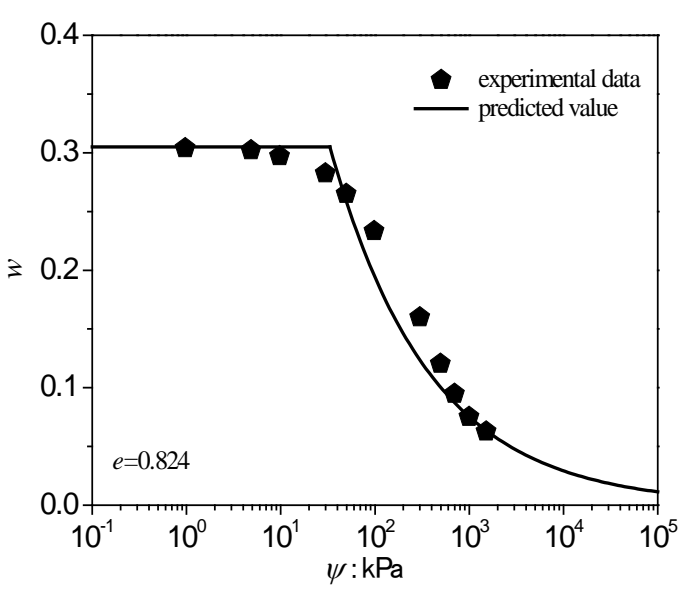

(a)

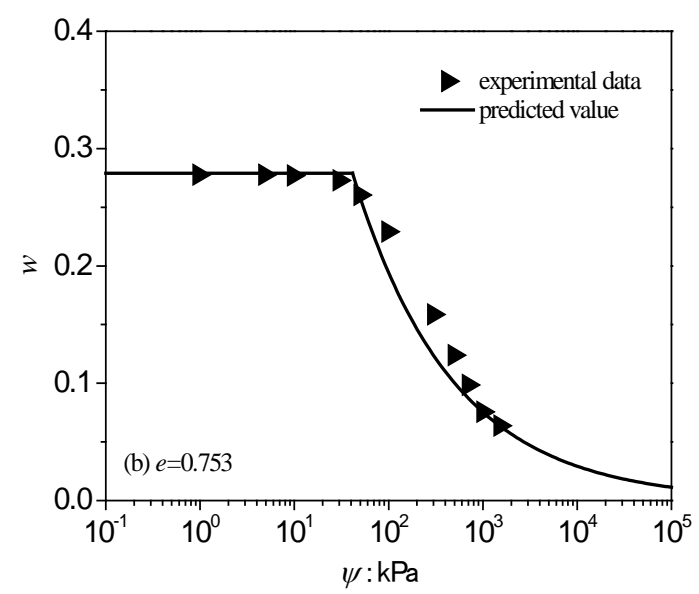

(b)

Figure 11. Measured and predicted SWCCs for Guangxi expansive soils at deformed state at (a) $e=0.824 ;$ (b) $e=0.753$ (data after Miao et al. [42]).

\subsection{Saskatchewan Silt}

The change of the SWCCs with the variation of initial void ratios for pressure plate cells tests performed by Huang [43] on the Saskatchewan silt was simulated in this section for further model validation. The physical properties of Saskatchewan silt are shown in Table 5. The specimens were compressed in stainless sample rings by conventional odometer under the same consolidation pressures. Two groups of tests were conducted. In the first group of tests (T1), the initial void ratios of the specimens were $0.692,0.540,0.528,0.501,0.483$, and 0.466 , respectively, while the initial void ratios of specimens in the second group of tests (T2) were $0.525,0.513,0.490,0.474,0.454$, and 0.426 , respectively.

The void ratio of the specimen at the loosest state $e_{0}=0.692$ for $\mathrm{T} 1$ was regarded as the initial void ratio at reference state. The calibrated SWCC parameters of T1 at reference state for the first tests $\left(D_{0}=2.640, \psi_{a 0}=7.78 \mathrm{kPa}\right)$ were obtained as shown in Figures 12 and 13, respectively. The corresponding air-entry values at deformed state are presented in Table 2.

Table 5. Physical properties of Saskatchewan silt (data after Huang [43]).

\begin{tabular}{ccccc}
\hline Relative Density & Natural Water Content (\%) & Liquid Limit (\%) & Plastic Limit (\%) & Plastic Index (\%) \\
\hline 2.68 & 0.86 & 22.2 & 16.6 & 5.6 \\
\hline
\end{tabular}

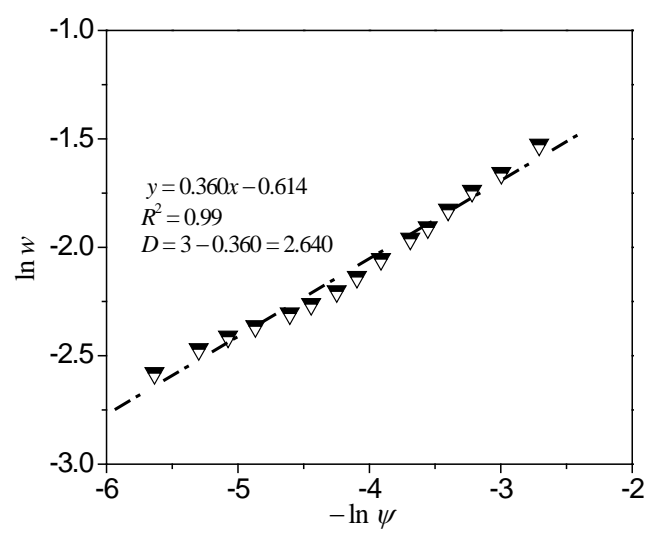

Figure 12. Determination of the values of fractal dimension at reference state through plotting experimental data of $\ln w$ against $(-\ln \psi)$ for Saskatchewan silt (T1) with $e_{0}=0.692$. 


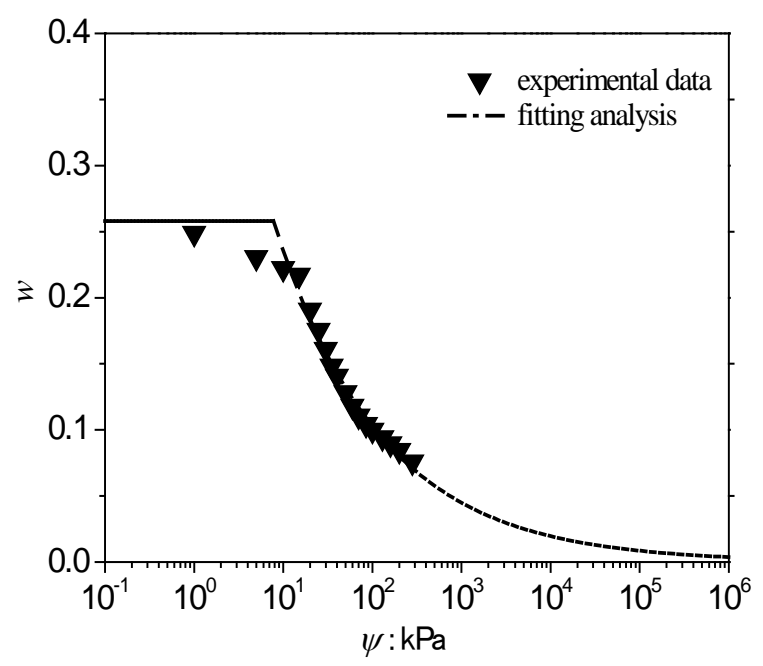

Figure 13. Determination of air-entry values at reference state through fitting Equation (12) to the experimental SWCCs for Saskatchewan silt (T1) with $e_{0}=0.692$.

Figure 14 presents the comparison of the experimental SWCCs and their predictions, demonstrating that the SWCCs of unsaturated Saskatchewan silt (T1) with the variation of initial void ratios were captured well.

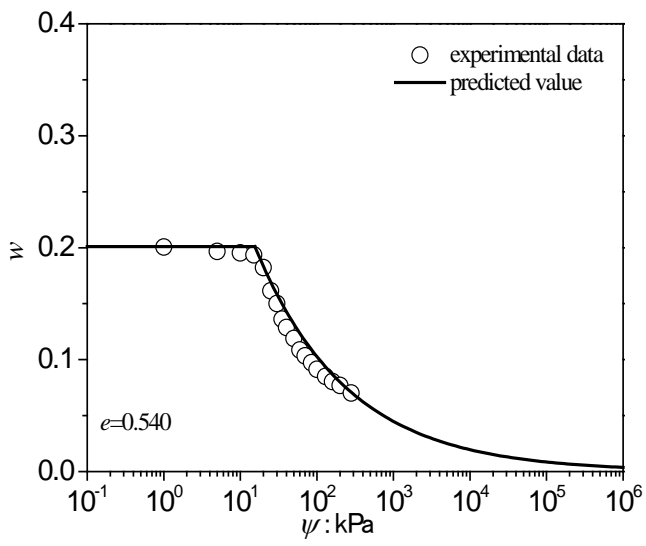

(a)

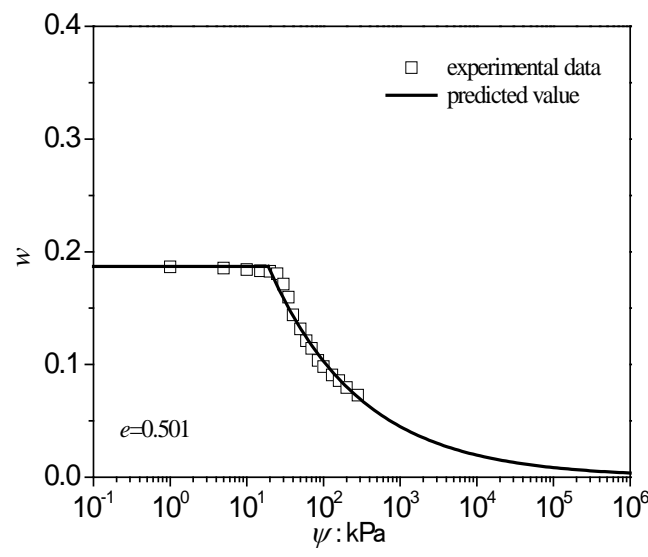

(c)

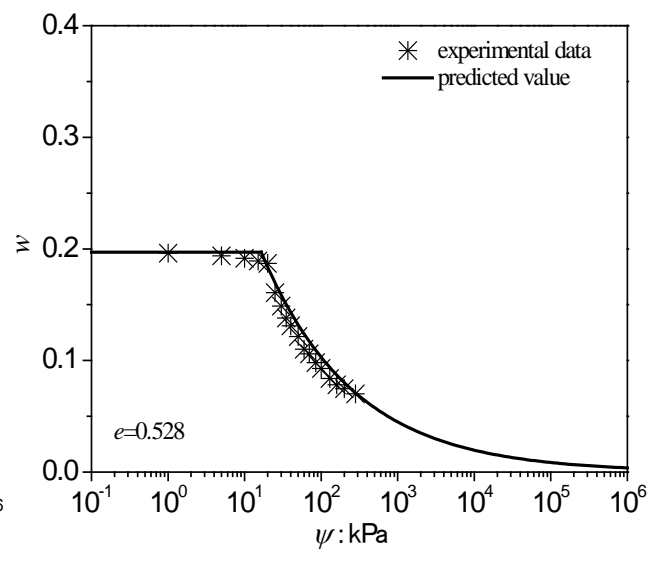

(b)

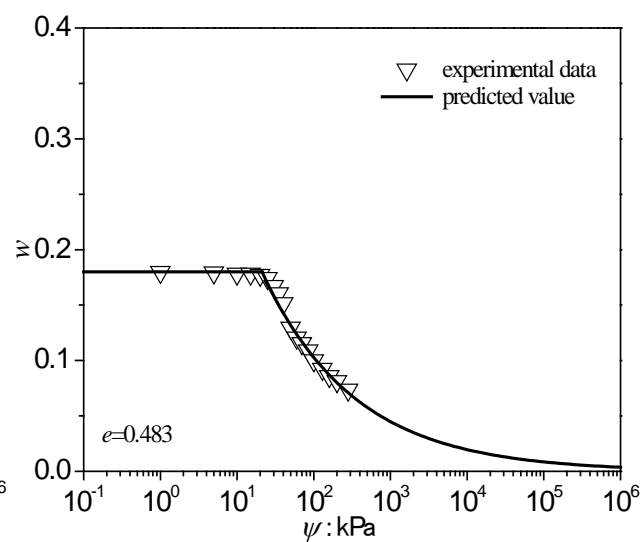

(d)

Figure 14. Cont. 


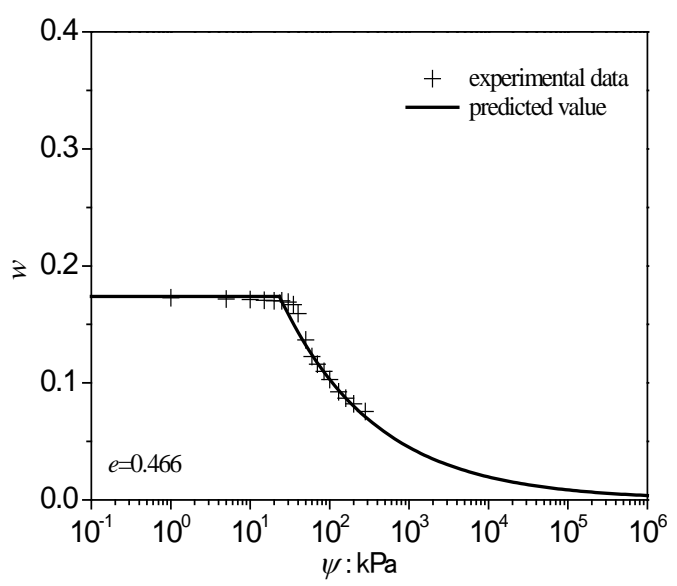

(e)

Figure 14. Measured and predicted SWCCs for Saskatchewan silt specimens (T1) at deformed state at (a) $e=0.540 ;$ (b) $e=0.528$; (c) $e=0.501 ;$ (d) $e=0.483$; (e) $e=0.466$ (data after Huang [43]).

The void ratio of the specimen at the loosest state $e_{0}=0.525$ for T2 was regarded as the initial void ratio at reference state. The calibrated SWCC parameters of Saskatchewan silt of T2 at reference state for the second tests $\left(D_{0}=2.604, \psi_{a 0}=17.71 \mathrm{kPa}\right)$ were obtained as shown in Figures 15 and 16 , respectively. The corresponding air-entry values at deformed state are presented in Table 2.

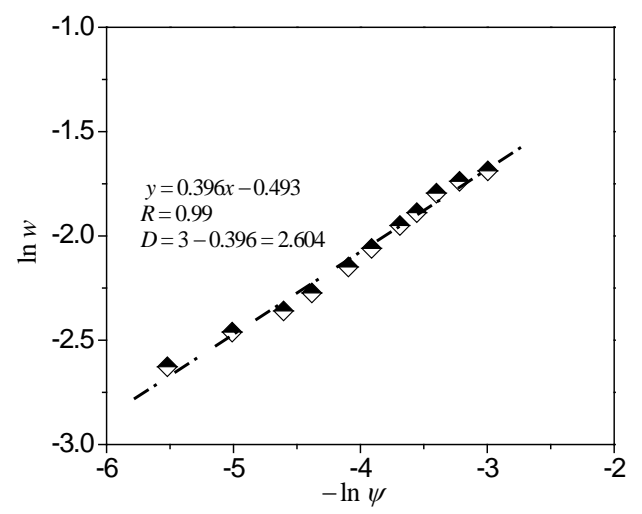

Figure 15. Determination of the values of fractal dimension at reference state through plotting experimental data of $\ln w$ against $(-\ln \psi)$ for Saskatchewan silt (T2) with $e_{0}=0.525$.

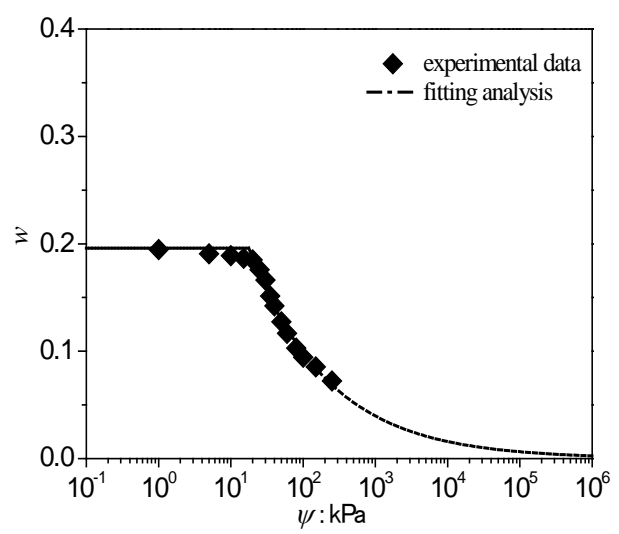

Figure 16. Determination of air-entry values at reference state through fitting Equation (12) to the experimental SWCCs for Saskatchewan silt (T2) with $e_{0}=0.525$. 
Figure 17 presents the comparison of the experimental SWCCs and their predictions, demonstrating that the SWCCs of unsaturated Saskatchewan silt (T2) with the variation of initial void ratios were captured well.

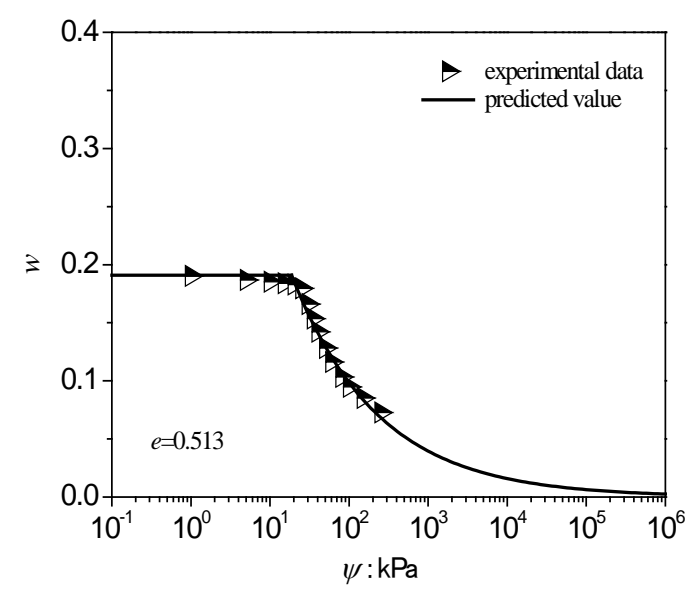

(a)

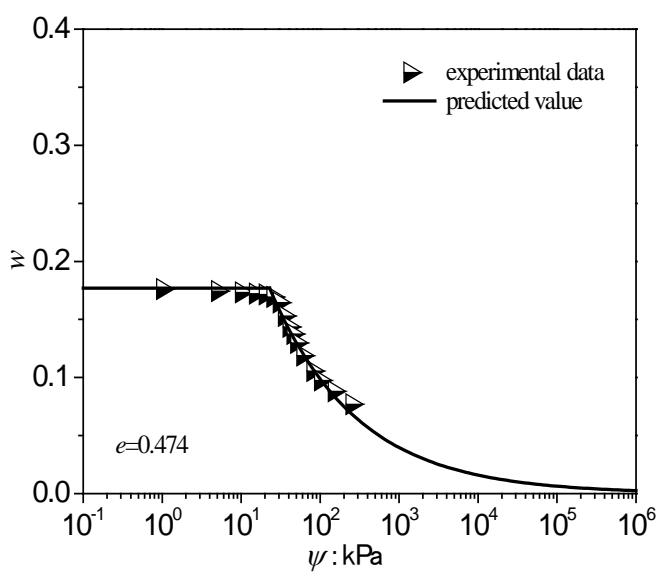

(c)

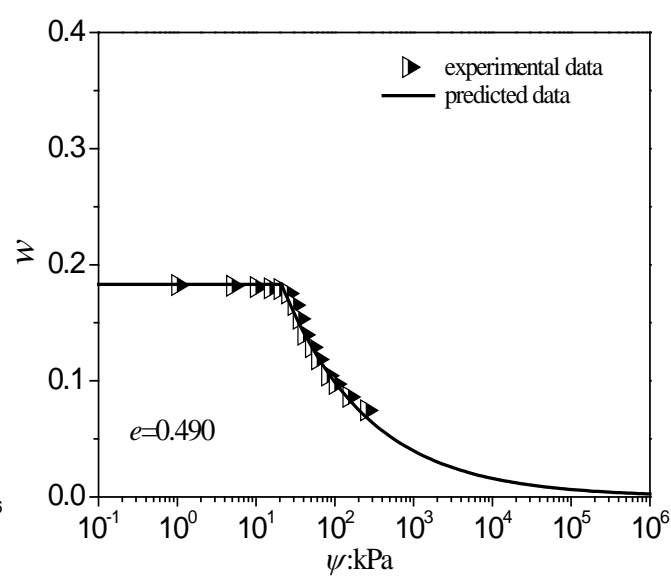

(b)

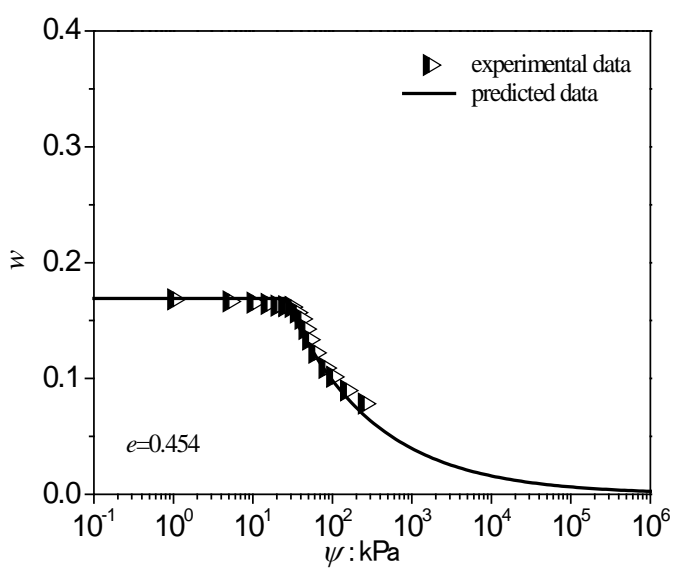

(d)

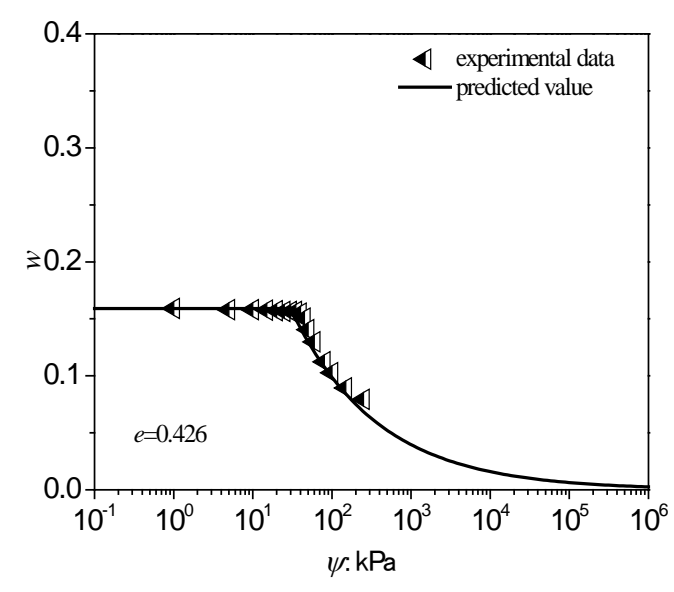

(e)

Figure 17. Measured and predicted SWCCs for Saskatchewan silt specimens (T2) at deformed state at (a) $e=0.513$; (b) $e=0.490$; (c) $e=0.474 ;$ (d) $e=0.454$; (e) $e=0.426$ (data after Huang [43]). 


\subsection{Loess}

Wang et al. [44] conducted a series of laboratory tests to investigate the effect of dry density and temperature on the SWCC of Xi'an loess. The physical properties of Saskatchewan silt are shown in Table 6. The compacted samples with different densities of $1.2 \mathrm{~g} / \mathrm{cm}^{3}, 1.4 \mathrm{~g} / \mathrm{cm}^{3}, 1.5 \mathrm{~g} / \mathrm{cm}^{3}$, and $1.6 \mathrm{~g} / \mathrm{cm}^{3}$, respectively, were prepared and tested by the high-speed centrifuge method. The void ratio of a specimen at the loosest state $\left(e_{0}=1.23\right)$ was regarded as the initial void ratio at reference state. The experimental temperatures were controlled at $5{ }^{\circ} \mathrm{C}, 15^{\circ} \mathrm{C}, 25^{\circ} \mathrm{C}$, and $35^{\circ} \mathrm{C}$, respectively. For model validation, experimental data at $5{ }^{\circ} \mathrm{C}$ was employed. The parameters of the loess at reference state $\left(D_{0}=2.825, \psi_{a 0}=0.55 \mathrm{kPa}\right)$ were obtained as shown in Figures 18 and 19, respectively, while the corresponding air-entry values at deformed state with various initial void ratios (i.e., $e_{0}=0.88,0.75$, and 0.72 , respectively) are shown in Table 2. It is shown in Figure 18 that the fitting correlation coefficient is up to 1.00, which highlights that the SWCCs of loess specimens have significant fractal features.

Table 6. Physical properties of Xi'an loess (data after Wang et al. [44]).

\begin{tabular}{cccc}
\hline Depth & Liquid Limit (\%) & Plastic Limit (\%) & Plastic Index (\%) \\
\hline 2.68 & 30.7 & 18.4 & 12.3 \\
\hline
\end{tabular}

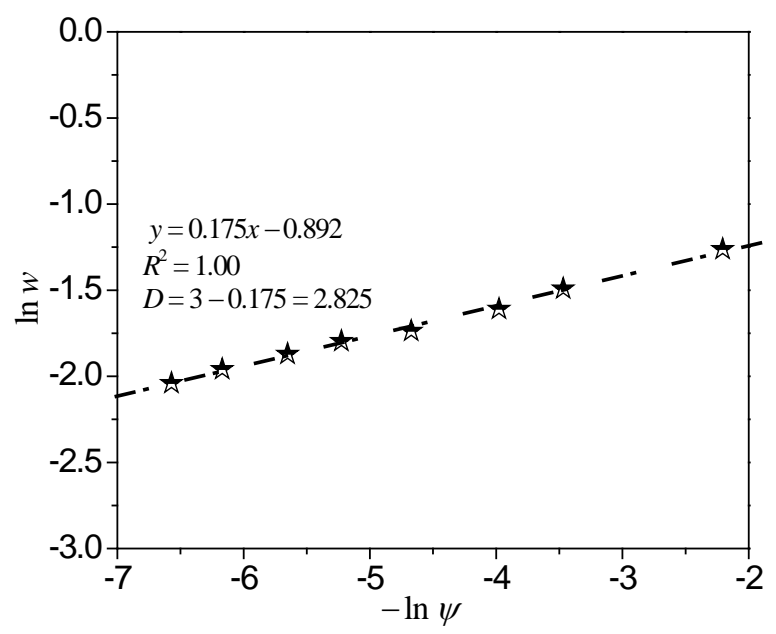

Figure 18. Determination of the values of fractal dimension at reference state through plotting experimental data of $\ln w$ against $(-\ln \psi)$ for loess with $e_{0}=1.230$.

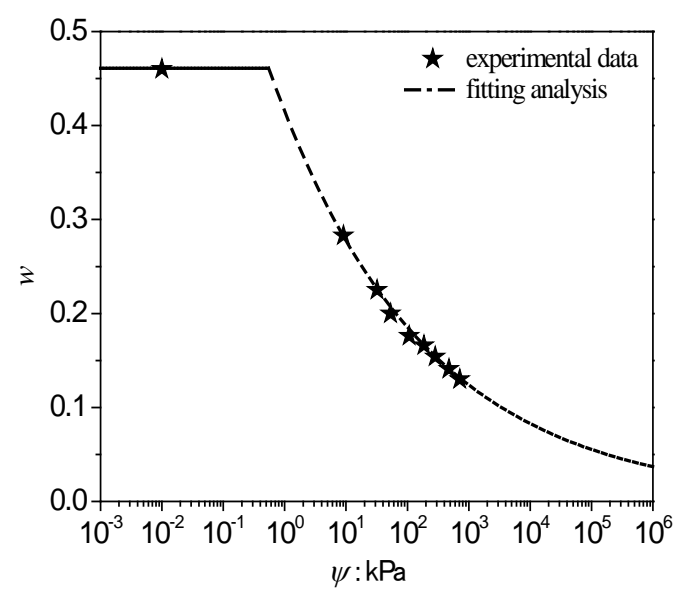

Figure 19. Determination of air-entry values at reference state through fitting Equation (12) to the experimental SWCCs for loess with $e_{0}=1.230$. 
The model prediction in terms of variation of initial void ratio is shown in Figure 20. A very good agreement is obtained with the experimental data, which demonstrates the capability of the model in capturing the change of SWCCs with void ratio for unsaturated soils.

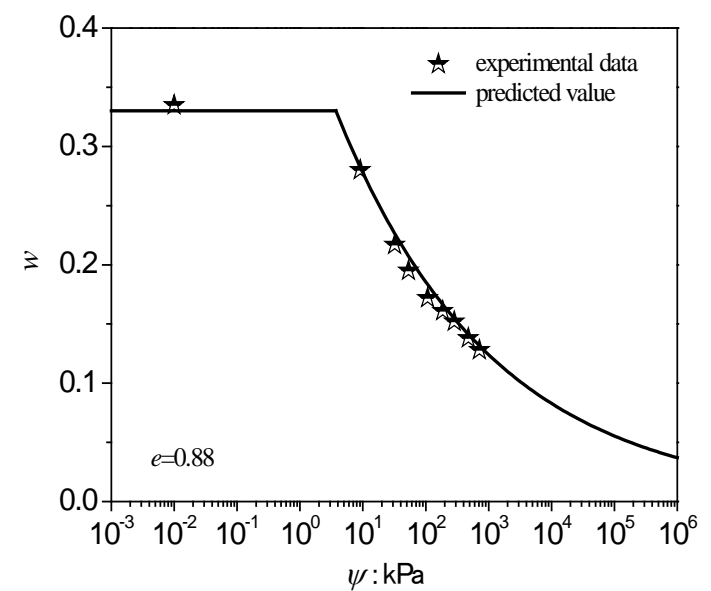

(a)

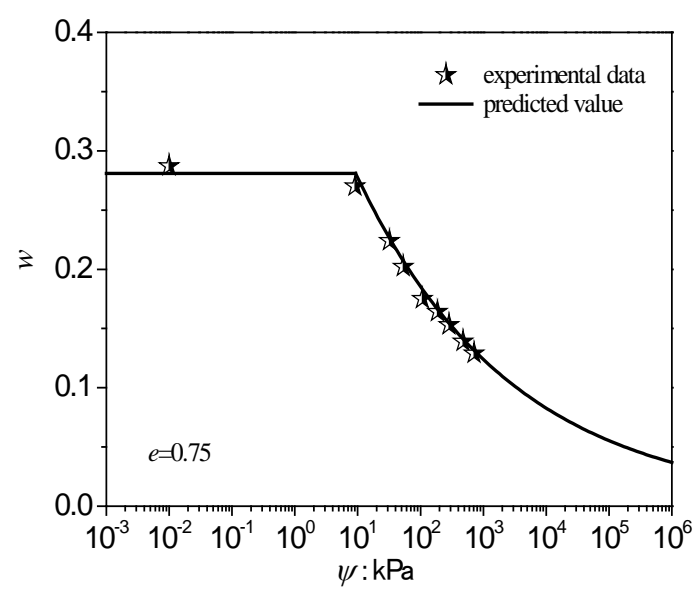

(b)

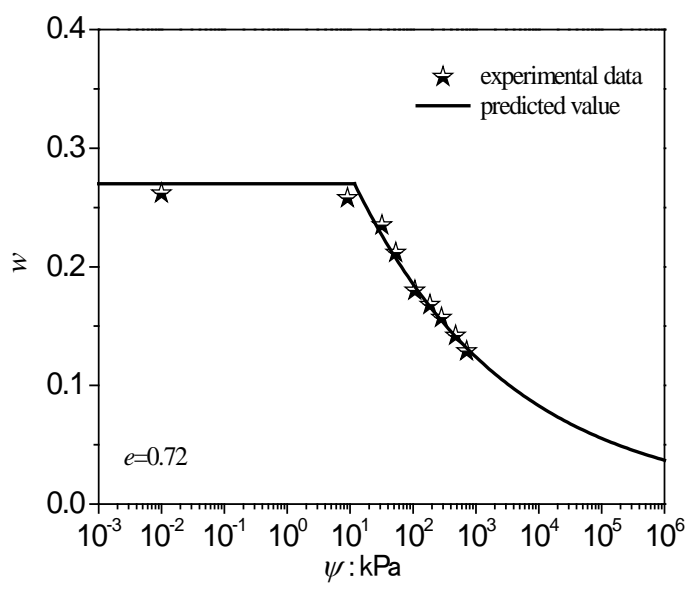

(c)

Figure 20. Measured and predicted SWCCs for Xi'an loess specimens at deformed state at (a) $e=0.88$; (b) $e=0.75$; (c) $e=0.72$ (data after Wang et al. [44]).

\section{Discussion}

There are generally three forms of SWCC expression, including gravimetric water content-suction curve ( $w-\psi$ curve), volumetric water content-suction curve ( $\theta-\psi$ curve), and degree of saturation-suction curve $\left(S_{r}-\psi\right.$ curve). In the current study, the theoretical principle of the proposed model is illustrated in Figure 1, where the SWCC presents a type of "broom shape" distribution in terms of the gravimetric water content. If it is necessary to obtain the SWCCs expressed by volumetric water content or degree of saturation, the gravimetric water content can be converted to the volumetric water content or degree of saturation. Respectively, the transformation formulas are expressed as

$$
\begin{gathered}
\theta=w G_{S} /(1+e) \\
S_{r}=w G_{S} / e
\end{gathered}
$$

In the drying process, water drains through large pores when the suction is low, which means the particles around large pores are gradually subjected to capillary pressure. As a result, the size of large 
pores decreases gradually. As the suction increases, small pores begin to drain water and the pore size is reduced correspondingly, leading to the shrinkage of the macroscopic volume of soils. The larger the initial void ratio, the more obvious this phenomenon. In the above process, it is only when the water is drained that the pore size can be reduced, and the drainage of water occurs firstly at large pores, and then at small pores. Hence, the radius of pores starting to drain water under a certain suction can be approximatively seen as its initial size. In contrast, in the wetting process, the drainage of water has been completed, and the volume shrinkage of large and small pores has also finished. So, the pore-size distribution characteristics at this stage have great difference from that in saturated state, which leads to the phenomenon of SWCC hysteresis. It should be stated that only the influence of initial void ratio on SWCC in drying path was investigated in this work, while the scenario for SWCC in wetting path will be studied in the future study.

\section{Conclusions}

A simple and efficient fractal-based approach capable of capturing effects of initial void ratio was presented for the SWCC of unsaturated soils. In terms of the experimental data, the SWCCs of the unsaturated soils at different initial void ratios were found to be mainly controlled by the air-entry value, while the fractal dimension could be assumed to be constant. In contrast to the complexity of existing models, only two parameters (i.e., fractal dimension $D$ and air-entry value $\psi_{\mathrm{a}}$ ) were employed in the current model. Determination of the model parameters with clear physical meaning were elaborated. The application of the model to a wide range of experimental data from the tests conducted in the current work, as well as the literatures, was examined. Good agreement was obtained between the experimental data and the model predictions in all of the cases considered.

Author Contributions: The research study was carried out successfully with contribution from all authors. The main research idea and manuscript preparation were contributed by G.T. and Q.C.; Y.C. contributed on the manuscript preparation and performed the correlative experiment. L.K. and H.X. gave several suggestions from the industrial perspectives. Y.X. assisted on finalizing research work and manuscript. All authors revised and approved the publication of the paper.

Acknowledgments: The financial support from the National Key R\&D Program of China (No. 2016YFC0502208), National Natural Science Foundation of China (No. 51708189 and 51409097), and Research project of Hubei Provincial Education Department (No. D20161405) are gratefully acknowledged.

Conflicts of Interest: The authors declare no conflict of interest.

\section{References}

1. Fredlund, D.G.; Xing, A.; Fredlund, M.D.; Barbour, S.L. Relationship of the unsaturated soil shear strength to the soil-water characteristic curve. Can. Geotech. J. 1996, 33, 440-448. [CrossRef]

2. Wheeler, S.J. Inclusion of specific water volume within an elasto-plastic model for unsaturated soil. Can. Geotech. J. 1996, 33, 42-57. [CrossRef]

3. Assouline, S. A model for soil relative hydraulic conductivity based on the water retention characteristic curve. Water Resour. Res. 2001, 37, 265-271. [CrossRef]

4. Gallipoli, D.; Gens, A.; Sharma, R.; Vaunat, J. An elasto-plastic model for unsaturated soil incorporating the effects of suction and degree of saturation on mechanical behaviour. Geotechnique 2003, 53, 123-135. [CrossRef]

5. Fredlund, D.G.; Rahardjo, H.; Fredlund, M.D. Unsaturated Soil Mechanics in Engineering Practice; John Wiley \& Sons: Hoboken, NJ, USA, 2012; Volume 132, pp. 286-321.

6. Van Genuchten, M.T. A closed-form equation for predicting the hydraulic conductivity of unsaturated soils. Soil Sci. Soc. Am. J. 1980, 44, 892-898. [CrossRef]

7. Fredlund, D.G.; Xing, A. Equations for the soil-water characteristic curve. Can. Geotech. J. 1994, 31, 521-532. [CrossRef]

8. Haj, K.M.A.A.; Standing, J.R. Soil water retention curves representing two tropical clay soils from Sudan. Geotechnique 2015, 66, 1-14.

9. Brooks, R.H. Hydraulic Properties of Porous Media; Colorado State University: Fort Collins, CO, USA, 1964; Volume 3, pp. 352-366. 
10. Romero, E.; Vecchia, G.D.; Jommi, C. An insight into the water retention properties of compacted clayey soils. Geotechnique 2011, 61, 313-328. [CrossRef]

11. Simms, P.H.; Yanful, E.K. Predicting soil-water characteristic curves of compacted plastic soils from measured pore-size distributions. Geotechnique 2002, 52, 269-278. [CrossRef]

12. Chan, T.P.; Govindaraju, R.S. A new model for soil hydraulic properties based on a stochastic conceptualization of porous media. Water Resour. Res. 2003, 39, 1195. [CrossRef]

13. Salager, S.; Nuth, M.; Ferrari, A.; Laloui, L. Investigation into water retention behaviour of deformable soils. Can. Geotech. J. 2013, 50, 200-208. [CrossRef]

14. Zhou, A.-N.; Sheng, D.; Carter, J.P. Modelling the effect of initial density on soil-water characteristic curves. Geotechnique 2012, 62, 669-680. [CrossRef]

15. Assouline, S. Modeling the relationship between soil bulk density and the water retention curve. Vadose Zone J. 2006, 5, 554-562. [CrossRef]

16. Ng, C.W.W.; Pang, Y.W. Influence of stress state on soil-water characteristics and slope stability. J. Geotech. Geoenviron. Eng. 2000, 126, 157-166. [CrossRef]

17. Gallipoli, D.; Wheeler, S.J.; Karstunen, M. Modelling the variation of degree of saturation in a deformable unsaturated soil. Geotechnique 2003, 53, 105-112. [CrossRef]

18. Wheeler, S.J.; Sharma, R.S.; Buisson, M.S.R. Coupling of hydraulic hysteresis and stress-strain behaviour in unsaturated soils. Geotechnique 2003, 53, 41-54. [CrossRef]

19. Sun, D.A.; Sheng, D.; Cui, H.B.; Sloan, S.W. A density-dependent elastoplastic hydro-mechanical model for unsaturated compacted soils. Int. J. Numer. Anal. Methods Geomech. 2007, 31, 1257-1279. [CrossRef]

20. Khalili, N.; Habte, M.A.; Zargarbashi, S. A fully coupled flow deformation model for cyclic analysis of unsaturated soils including hydraulic and mechanical hystereses. Comput. Geotech. 2008, 35, 872-889. [CrossRef]

21. Miller, G.A.; Khoury, C.N.; Muraleetharan, K.K.; Liu, C.; Kibbey, T.C.G. Effects of soil skeleton deformations on hysteretic soil water characteristic curves: Experiments and simulations. Water Resour. Res. 2008, 44, 137-148. [CrossRef]

22. Nuth, M.; Laloui, L. Advances in modelling hysteretic water retention curve in deformable soils. Comput. Geotech. 2008, 35, 835-844. [CrossRef]

23. Masin, D. Predicting the dependency of a degree of saturation on void ratio and suction using effective stress principle for unsaturated soils. Int. J. Numer. Anal. Methods Geomech. 2010, 34, 73-90. [CrossRef]

24. Sheng, D.; Zhou, A.N. Coupling hydraulic with mechanical models for unsaturated soils. Can. Geotech. J. 2011, 48, 826-840. [CrossRef]

25. Tarantino, A. A water retention model for deformable soils. Geotechnique 2009, 59, 751-762. [CrossRef]

26. Gallipoli, D.; Bruno, A.W.; Onza, F.D.; Mancuso, C. A bounding surface hysteretic water retention model for deformable soils. Geotechnique 2015, 65, 793-804. [CrossRef]

27. Wei, W.; Cai, J.; Hu, X.; Han, Q.; Liu, S.; Zhou, Y. Fractal analysis of the effect of particle aggregation distribution on thermal conductivity of nanofluids. Phys. Lett. A 2016, 380, 2953-2956. [CrossRef]

28. Wei, W.; Cai, J.; Hu, X.; Han, Q. An electrical conductivity model for fractal porous media. Geophys. Res. Lett. 2015, 42, 4833-4840. [CrossRef]

29. Cai, J.; Hu, X.; Xiao, B.; Zhou, Y.; Wei, W. Recent developments on fractal-based approaches to nanofluids and nanoparticle aggregation. Int. J. Heat Mass Transf. 2017, 105, 623-637. [CrossRef]

30. Cai, J.; Wei, W.; Hu, X.; Liu, R.; Wang, J. Fractal characterization of dynamic fracture network extension in porous media. Fractals 2017, 25, 1750023. [CrossRef]

31. Cai, J.; Hu, X. Fractal Theory in Porous Media and its Applications; Science Press: Beijing, China, 2015.

32. Zolfaghari, A.; Dehghanpour, H.; Xu, M. Water sorption behaviour of gas shales: II. Pore size distribution. Int. J. Coal. Geol. 2017, 179, 187-195. [CrossRef]

33. Shi, Y.; Yassin, M.R.; Dehghanpour, H. A modified model for spontaneous imbibition of wetting phase into fractal porous media. Colloids Surf. A Physicochem. Eng. Asp. 2018, 543, 64-75. [CrossRef]

34. Bird, N.R.A.; Perrier, E.; Rieu, M. The water retention function for a model of soil structure with pore and solid fractal distributions. Eur. J. Soil Sci. 2000, 51, 55-63. [CrossRef]

35. Xu, Y.F.; Sun, D.A. A fractal model for soil pores and its application to determination of water permeability. Physica A 2002, 316, 56-64. [CrossRef]

36. Russell, A.R. How water retention in fractal soils depends on particle and pore sizes, shapes, volumes and surface areas. Geotechnique 2014, 64, 379-390. [CrossRef] 
37. Huang, G.; Zhang, R. Evaluation of soil water retention curve with the pore-solid fractal model. Geoderma 2005, 127, 52-61. [CrossRef]

38. Khalili, N.; Khoshghalb, A.; Pasha, A.Y. A fractal model for volume change dependency of the water retention curve. Geotechnique 2015, 65, 141-146.

39. Tao, G.L.; Zhang, J.R. Two categories of fractal models of rock and soil expressing volume and size-distribution of pores and grains. Sci. Bull. 2009, 54, 4458-4467. [CrossRef]

40. Tao, G.L.; Zhang, J.R.; Zhuang, X.S.; Yang, L. Influence of compression deformation on the soil-water characteristic curve and its simplified representation method. J. Hydraul. Eng. 2014, 45, 1239-1245.

41. Russell, A.R.; Buzzi, O. A fractal basis for soil-water characteristics curves with hydraulic hysteresis. Geotechnique 2012, 62, 269-274. [CrossRef]

42. Miao, L.; Jing, F.; Houston, S.L. Soil-water characteristic curve of remolded expansive soils. In Proceedings of the Fourth International Conference on Unsaturated Soils, Carefree, Arizona, 2-6 April 2006; pp. 997-1004.

43. Huang, S. Evaluation and Laboratory Measurement of the Coefficient of Permeability in Deformable. Ph.D. Thesis, University of Saskatchewan, Saskatoon, SK, Canada, 1994.

44. Wang, T.H.; Lu, J.; Yue, C.K. Soil-water characteristic curve for unsaturated loess considering temperature and density effect. Rock Soil Mech. 2008, 29, 1-5.

(C) 2018 by the authors. Licensee MDPI, Basel, Switzerland. This article is an open access article distributed under the terms and conditions of the Creative Commons Attribution (CC BY) license (http:/ / creativecommons.org/licenses/by/4.0/). 